only one determination of the NIR spectrum of the feedstuff is required to estimate a large range of constituents. NIR can also be used to measure some functional properties of feedstuffs. Disadvantages include the need to acquire and analyse large (hundreds or sometimes thousands) sets of samples representing the range of NIR spectral diversity associated with various classes of the feedstuff (e.g. plant cultivars, agronomic, soil and seasonal conditions) to develop reliable and robust calibration equations. Conventional analysis is required for each constituent or attribute to determine the reference values necessary to develop the calibration equations. In addition, ongoing conventional analysis of subgroups of samples is needed indefinitely to validate and adjust calibration equations. Other constraints are that NIR instrumentation requires substantial capital investment, and considerable technical skills are required to develop and maintain calibration equations.

In a similar manner to the analysis of forages, NIR analysis of faeces allows estimation of many attributes of the diet of ruminants. Such estimation of diet from faecal NIR spectra depends on the similarity of the NIR spectra of forages and matching faeces (diet-faecal pairs) despite effects of digestion in the gastro-intestinal tract. Prediction of diet from faecal NIR spectra appears most reliable for forage diets. Thus many attributes of the diet selected by grazing ruminants (e.g. nitrogen content, digestibility, non-grass content) can be estimated when appropriate calibration equations are available.

In general NIRS is appropriate for organic constituents that comprise greater than about $1 \%$ of the feedstuff. NIRS is not generally suitable for mineral analysis although there are exceptions. Some functional as well as chemical properties of feedstuffs can be measured using NIRS. For example NIRS is often more satisfactory than the established laboratory procedures to estimate in vitro digestibility of forages. Also the voluntary intake of forage dry matter and digestible energy by ruminants can often be estimated more accurately from NIRS measurements of the forage than from constituents such as fibre or lignin.

Conclusions NIRS can be used to analyse many chemical and functional properties of animal feedstuffs. Reliable analysis depends on development and maintenance of appropriate calibration equations, and these require appreciable resources and skills.

\section{References}

Andres S, Murray I, Calleja A and Giraldez FJ 2005. J Near Spectroscopy 13, 301-311. Roberts CA, Workman J and Reeves JB 2004. Near-Infrared Spectroscopy in Agriculture. Agronomy Monograph No 44. American Society of Agronomy, Madison, Wisconsin, USA.

Williams P and Norris K 2001. Near-Infrared Technology in the Agricultural and Food Industries, 2nd Edn. American Association of Cereal Chemists, St Paul, Minnesota, USA

\title{
Australian Data for a Tropical Feeds Database
}

\author{
Peter R Martin ${ }^{1}$ and Rob M Dixon ${ }^{2}$ \\ ${ }^{1}$ DEEDI, Health and Food Sciences Precinct PO Box 156, Archerfield BC QLD 4108, Australia; ${ }^{2}$ The University of Queensland, QAAFI, PO Box 6014, \\ Rockhampton 4702, Australia \\ Email : Peter.Martin@deedi.qld.gov.au
}

Introduction: A public domain database providing information on tropical feeds would be valuable to livestock farmers and researchers both in Australia and internationally. The Animal Science Nutrition Laboratory of the Department of Employment, Economic Development and Innovation (DEEDI), Queensland Government, operates a central laboratory to provide an extensive range of nutritional analyses of pastures and other animal feedstuffs. Archival records date back more than 30 years. Data since 1995 has been stored in a digital format.

Detail: A Microsoft Access database currently contains about 10,000 records. This is divided about equally between forages (pasture samples immediately oven-dried or forages conserved as hay or silage) and concentrates (mainly grains or by-products of cereals or legumes, and oilseed meals).

For data storage most of the samples have been categorised and named as described by Göhl (1975). The number of records within each of these categories is shown in Table 1. Where information is available entries are further described according to common name, variety, part

Table 1 Categories and number of entries within the Animal Science database

\begin{tabular}{llll}
\hline \hline Code & Category & Description & Number \\
\hline A & Grass & Grasses and mixed pastures & 2959 \\
B & Legume & Pasture and browse legumes & 649 \\
C & Forage & Miscellaneous forage and & 1203 \\
& & browse plants \\
D & Fruit & Fruits and vegetables & 18 \\
E & Root & Root crops & 118 \\
F & Cereal & Cereal grains & 2723 \\
G & Oilseed & Oilseeds, grain, meals and cakes & 1211 \\
H & Animal Origin & Feeds of animal origin & 901 \\
I & Misc Feed & Miscellaneous feedstuffs & 423 \\
K & Premixes & Defined feed additives & 30 \\
\hline \hline
\end{tabular}


of the plant and treatment. Samples submitted to the laboratory are often poorly identified with approximately $50 \%$ of the database entries having little description beyond the category. This is particularly the case for the pasture species. Information is usually lacking on stage of growth and how the sample might represent either the pasture on offer or that selected by the animal and hence inclusion of these pasture samples might be considered inappropriate.

Depending on the feed type and the submitter's request, the analyses performed on a feedstuff could include dry matter, ash, total nitrogen, gross energy, amino acids, crude fat, fatty acids, crude fibre, neutral detergent fibre, acid detergent fibre, lignin, in vitro digestibility (measured using rumen fluid), water soluble carbohydrate, starch, amylose, beta glucans, $\mathrm{Ca}, \mathrm{P}, \mathrm{Na}$ and $\mathrm{K}$.
Conclusions: The Queensland Animal Science database contains nutritional data for a large number of tropical and sub-tropical animal feeds that potentially could be included in an international, public domain, feeds database. Because detailed information is lacking for the majority of 'pasture' samples, contributions might best be limited to concentrates, hay and silage. To ensure best quality of the data and the scientific outcomes, resources are needed to scrutinise the information in the database e.g. to confirm descriptions and to confirm the matching of formats and nomenclature.

\section{References}

Göhl B 1975. Tropical Feeds, Feeds Information Summaries and Nutritive Values (Unedited Version). FAO, Rome.

\title{
Tables of nutritive value for farm animals in tropical and Mediterranean regions: an important asset for improving the use of local feed resources
}

\author{
Gilles Tran ${ }^{1}$, Valérie Heuzé ${ }^{1}$, Denis Bastianelli ${ }^{2}$, Harry Archimède ${ }^{3}$ and Daniel Sauvant ${ }^{1,4}$ \\ ${ }^{1}$ Association Française de Zootechnie, 75231 Paris Cedex 05, France; ${ }^{2}$ CIRAD, Systèmes d'élevage et produits animaux, 34398 Montpellier Cedex 05, France; \\ ${ }^{3}$ INRA, UR143 Unité de Recherches Zootechniques, 97170 Petit-Bourg, France; ${ }^{4}$ AgroParisTech, UMR 791 MoSAR, 75231 Paris Cedex 05, France \\ Email: gilles.tran@gmail.com
}

\section{Introduction}

The optimisation of feed resources is of paramount importance and requires accurate feed values. Tables of feed composition and nutritive value are used to formulate diets that meet animal requirements at the lowest cost, thereby improving production results and farm productivity. In emerging and developing countries, and particularly those in tropical and Mediterranean areas, the demand for animal products has been steadily growing in the past decades, and so has the need for accurate feed information. However, even though many research data are published every year, they are rarely summarized in an easily available form, and users in these regions must often rely on data obtained in temperate countries or use obsolete or incomplete sources.

The Tables of nutritive values for farm animals in tropical and Mediterranean regions is a current project of INRA, CIRAD and AFZ (with partial support from the FAO) that aims to produce comprehensive tables for feed users in these areas. The tables are planned for release in 2013, either in paper or electronic form. In addition to AFZ staff, the project involves INRA and CIRAD researchers, and research organizations from other countries.

\section{Objectives}

The main objective is to create a compendium of up-to-date information on feed materials available to users in tropical, subtropical and Mediterranean regions. The project focuses on the following information:

- Feed nomenclature and descriptions: names, physical aspect (including pictures), availability, processes and environmental impact.

- Recommendations by livestock species, including cautionary information.

- Composition and nutritive values derived from feed databases and scientific literature.

For local users, the following benefits should be expected:

- Better identification, qualification and quantification of local feed resources.

- Better opportunities for livestock in sustainable integrated farming systems.

- Better use of local feeding practices and less reliance on imported techniques and feed materials.

- In the near future, it will also be possible to use the tables' framework for quantitative environmental data. 